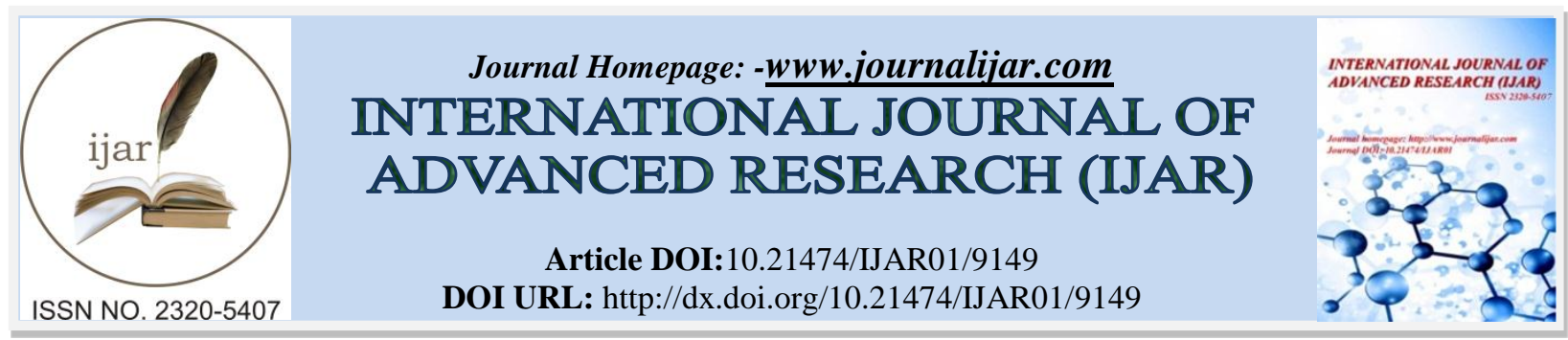

RESEARCH ARTICLE

\title{
A STUDY OF THE RELATIONSHIP BETWEEN INSULIN SENSITIVITY AND GLYCEMIC PROFILE IN WOMEN WITH POLYCYSTIC OVARY SYNDROME.
}

\section{Dr. N. Malaiarasi.}

\section{Manuscript Info}

Manuscript History

Received: 24 March 2019

Final Accepted: 26 April 2019

Published: May 2019

Key words:-

PCOS, Insulin, Infertility.
Abstract

PCOS is one of the leading causes of Infertility in females. Insulin resistance is a regular component of PCOS. Factors that ameliorate insulin resistance $\&$ reduce circulating Insulin levels could provide a new therapeutic modality for PCOS.

Copy Right, IJAR, 2019,. All rights reserved.

\section{Introduction:-}

PCOS a common endocrine disorder of premenopausal women is characterised by hyperandrogenic chronic anovulation. Kahn and collegues designated this as Type A syndrome. The typical morphology of polycystic ovaries was described by Chereau in 1844. Stein \& Leventhal in 1935 linked amenorrhea, infertility \& obesity while Burghen in 1980 associated hyperinsulinemia with this. Chang et al in 1983 showed higher Insulin during OGTT. Abnormalities in Insulin action are poorly detected by a single determination of either glucose or insulin levels Laakso.

\section{Materials and methodology:-}

Study design-

Cross sectional case control study.

\section{Study group -}

30, non diabetic females with PCOS in the age group of 15-40 years were screened for the study.

\section{Control group -}

30 apparently healthy, age matched, non diabetic females without PCOS were selected.

After overnight fasting of 12 hours, venous blood sampling drawn. Fasting blood glucose estimated by Standard glucose oxidase method. Fasting Insulin levels were assessed by Elisa Technique. 90 minutes after food intake, postprandial blood glucose estimated.

\section{Inclusion Criteria}

1. Newly diagnosed, Infertile PCOS women on no drug ( Rotterdam's criteria, 2007).

2. Age around $15-40$ years.

3. Non diabetic - Fasting Blood Sugar $<126 \mathrm{mg} / \mathrm{dl}$.

Postprandial Blood Sugar <200 mg / dl.

Attending as outpatients in the department of Obstetrics and Gynaecology, Government Rajaji Hospital, Madurai.

Corresponding Author:-Dr. N. Malaiarasi. 


\section{Exclusion Criteria}

1. PCOS cases on treatment.

2. Diabetes

3. Hypertension

4. ThyroidDisorder

5. Renal,Hepatic or Cardiovascular Disease

6. Pregnancy, Lactating women and women using oral contraceptives

7. Any Hormonal Medications within previous 6 weeks

All healthy Euthyroid women who were not taking any medication known to affect sex hormone or carbohydrate metabolism were included as subjects. Control women were matched for age, weight, BMI, normal Blood glucose levels and regular menstruation with no hirsuitism.

\section{Observation and Results:-}

Using Student' $t$ ' test and Chi square test data were analysed using SPSS 16 Software.

Table I:-Age

\begin{tabular}{|l|l|l|l|}
\hline Age in years & Cases & Controls & p value \\
\cline { 1 - 2 } 19-24 & 15 & 7 & 0.064 \\
\cline { 1 - 2 } Not Significant \\
\cline { 1 - 2 }-29 & 12 & 16 & \\
\cline { 1 - 2 }-34 & 2 & 7 & \\
\cline { 1 - 3 } Total & 1 & 0 & \\
\hline
\end{tabular}

\section{AGE COMPARISON}

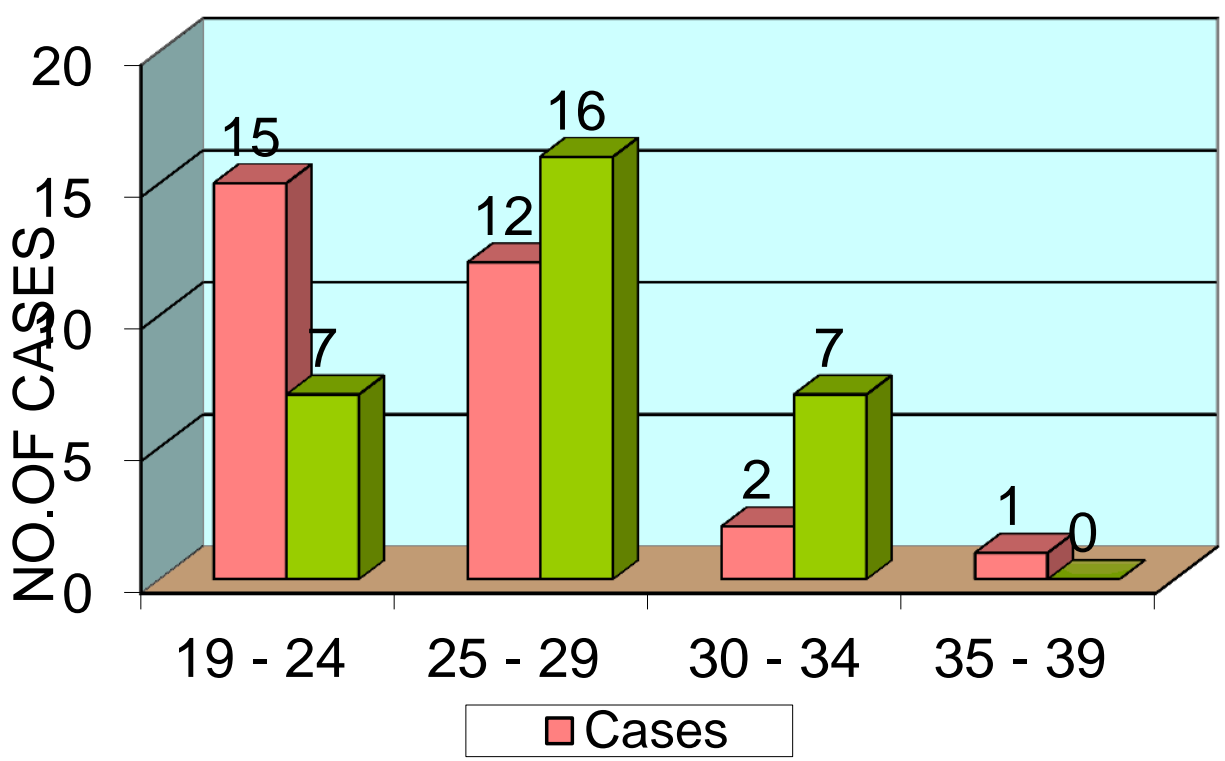

Table II :-BMI kg/m² Cases versus Controls

\begin{tabular}{|l|l|l|l|}
\hline BMI & Cases & Controls & p value \\
\hline$<20$ & 2 & 0 & 0.025 Significant \\
\cline { 1 - 2 } $20.1-22$ & 2 & 0 & \\
\cline { 1 - 2 } $22.1-24$ & 10 & 0 & \\
\cline { 1 - 2 }$-1-26$ & 10 & 2 & \\
\cline { 1 - 2 } 26 & 6 & 28 & \\
\cline { 1 - 3 } Total & 30 & 30 & \\
\hline
\end{tabular}




\section{BMI COMPARISON}

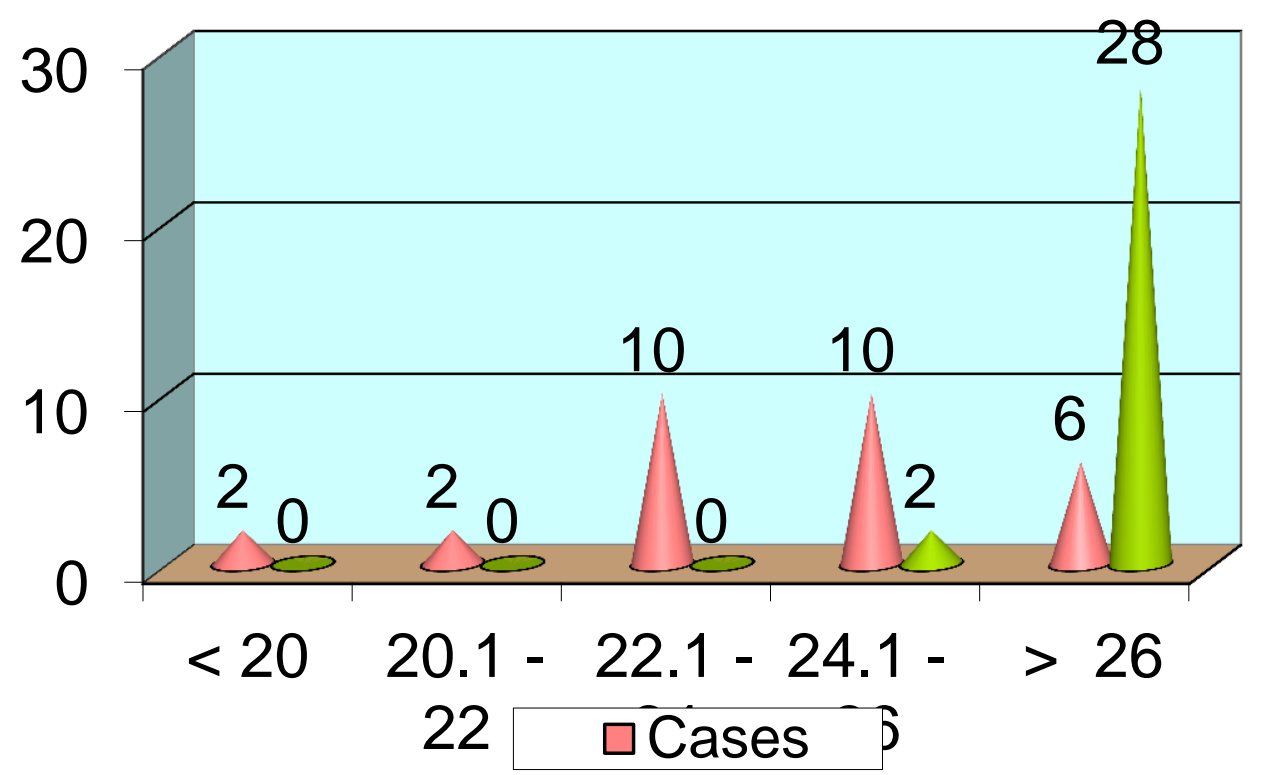

Table III:-Fasting Insulin Level $\mu \mathrm{u} / \mathrm{ml}$

\begin{tabular}{|c|c|c|c|}
\hline Fasting Insulin level & Cases & Controls & $\mathrm{p}$ value \\
\hline $5-9$ & 7 & 30 & \multirow[t]{6}{*}{$<0.001$ Significant } \\
\hline $10-14$ & 6 & 0 & \\
\hline $15-19$ & 6 & 0 & \\
\hline $20-24$ & 9 & 0 & \\
\hline$>25$ & 2 & 0 & \\
\hline Total & 30 & 30 & \\
\hline
\end{tabular}

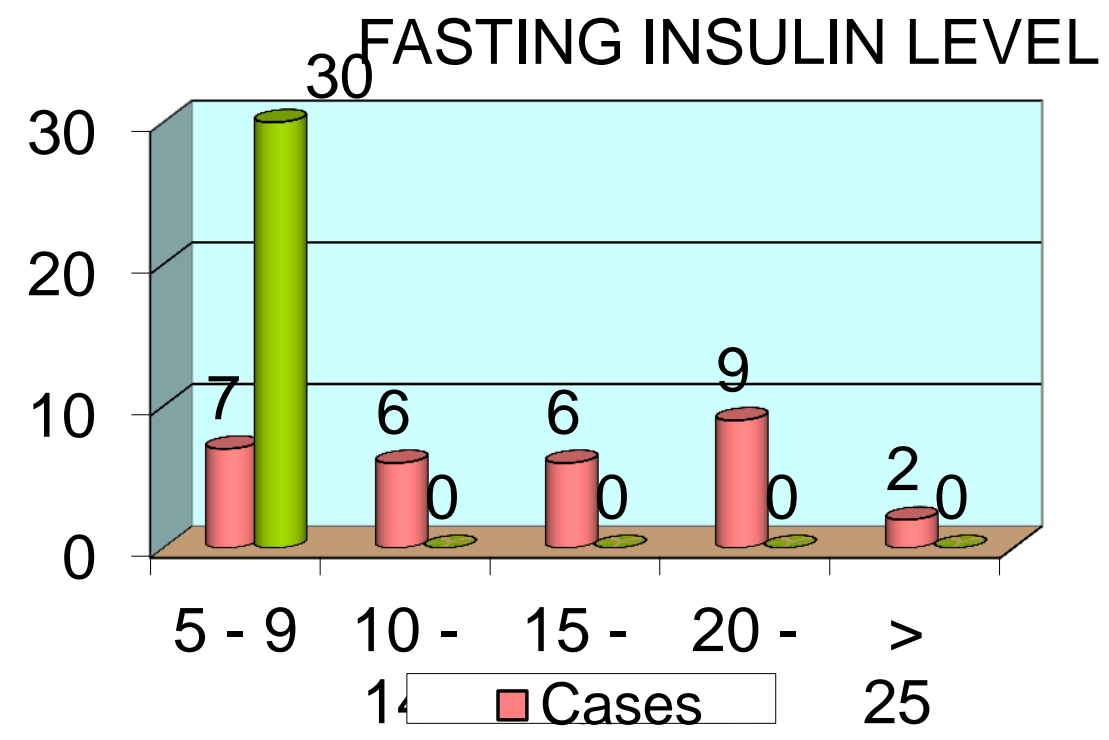


Table IV:-Fasting Blood Glucose levels in $\mathrm{mg} / \mathrm{dl}$.

\begin{tabular}{|l|l|l|l|}
\hline Fasting blood glucose & Cases & Controls & p value \\
\hline$<70$ & 3 & 7 & $<0.001$ Significant \\
\hline $71-80$ & 13 & 19 & \\
\cline { 1 - 3 }-90 & 13 & 4 & \\
\hline Total & 1 & 0 & \\
\hline
\end{tabular}

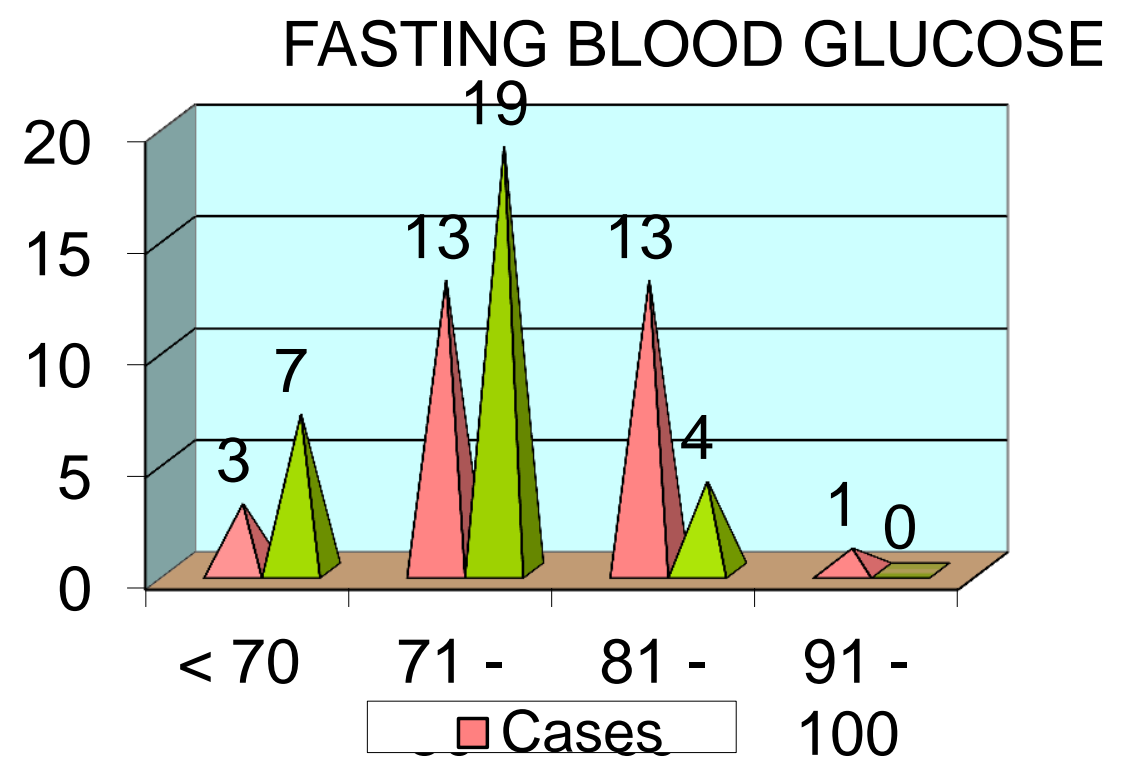

Table V:-Clinical and Biochemical features

\begin{tabular}{|c|c|c|c|c|c|}
\hline & \multicolumn{2}{|l|}{ Cases } & \multicolumn{2}{|c|}{ Controls } & \\
\hline & Mean & SD & Mean & SD & p'value \\
\hline Age in years & 24.4 & 4.6 & 26.8 & 5.3 & 0.064 Not Sig \\
\hline BMI & 24.1 & 4.7 & 27.7 & 7.2 & 0.025 Significant \\
\hline Fasting Insulin & 17.8 & 8.1 & 7.2 & 3.4 & $<0.001$ Significant \\
\hline Fasting blood sugar & 80.7 & 12.6 & 74.2 & 10.9 & $<0.001$ Significant \\
\hline
\end{tabular}

Reference range of Insulin is $2-25 \mu \mathrm{U} / \mathrm{ml}$

\section{Glucose Insulin value $<7.2$}

Approximately $50 \%$ to $70 \%$ of all women with PCOS have some degree of Insulin resistance. Obesity, Stress and Ageing substantiates to this. Obesity per se or increased central adiposity are responsible for the associated defects in Insulin action Ovesen et al. Insulin insensitivity contributes to Hyperandrogenism which is responsible for the signs and symptoms of PCOS. Early detection and treatment of Insulin resistance reduce the incidence and severity of Diabetes mellitus, dyslipidemia, Hypertension and cardiovascular disease.

Polycystic ovary morphology has been reported to be inherited as an autosomal dominant Carey et al.

Women with PCOS are resistant to the action of insulin and compensates for this abnormality by a period of hypersecretion of insulin by the pancreatic beta cell and a decrease in Insulin clearance. Circulating Insulin to Cpeptide molar ratios are increased in PCOS suggesting decreased hepatic extraction of Insulin. Hyperandrogenism and chronic anovulation occur by a stimulation of ovarian and adrenal androgen biosynthesis as a trophic hormone; suppression of sex hormone binding globulin levels ( thus increasing the bioavailable pool of androgens ) and through direct hypothalamic pituitary effects altering the pattern of circulating gonadotropins in favour of predominant LH levels. Because of the pulsatile nature of gonadotropin release, a single blood sample can fail to detect an increased LH/ FSH ratio. 


\section{Discussion:-}

Euglycemic clamp suggested by Dunaif et al (1989) is a gold standard method for evaluating Insulin sensitivity which states that the amount of infused glucose equals the amount taken by the tissues. Glucose utilisation is expressed as a function of muscle mass. Female adipocytes are more sensitive to insulin mediated glucose uptake Foley JF. Visceral obesity and PCOS has a deleterious effect on Insulin sensitivity. Fasting hyperinsulinemia is usually considered as a measure of Insulin action. Basal and glucose stimulated Hyperinsulinemia are well reported in obese PCOS. In my study BMI showed 0.025 significant 'p' value with fasting blood glucose and Insulin analysed showed $<0.001$ significant' p' value.

\section{Conclusion:-}

PCOS remains a syndrome with clinical manifestations of menstrual irregularities, signs of androgen excess and obesity along with Insulin resistance and elevated serum LH levels. If Insulin is to produce ovarian hyperandrogenism in women, polycystic ovarian changes like Theca cell hyperplasia must be present that predispose the ovaries to secrete excess androgens. In normal women Insulin does not appear to have any acute effects on ovarian function under physiological circumstances.

The association between insulin resistance and PCOS has led to the discovery that insulin is an important reproductive hormone and that insulin signaling in the CNS is critical for ovulation. This insight was directly translated into a novel therapy for PCOS with ISDs.

Framework of PCOS treatment include lifestyle interventions such as diet and exercise along with agents that improve insulin sensitivity. This results in the beneficial changes in the phenotype with increased menstrual \& ovulatory frequency, pregnancy \& decreased hirsuitism. These women may be more likely to benefit from therapies that lower circulating Insulin levels. Fasting Glucose Insulin ratio may be a useful test for identifying PCOS women with Insulin resistance.

\section{Bibliography:-}

1. Burghen GA, Givens JR, Kitabchi AE (1980 ).Correlation of hyperandrogenism with hyperinsulinism in polycystic ovarian disease. J Clin Endocrine metabolism50,113-116.

2. Chang RJ, Nakamura RM,Judd HL\& Kaplan SA(1983). Insulin resistance in nonobese patients withPCOD. J Clin Endocrine metabolism57,356-359.

3. Chereau A (1844) Memoires pour Servir a l'etude des Maladies des ovaries. Masson et Cie.Paris, France

4. Park KH, Kim JY et al.PCOS \& Insulin resistance. Int J Gynaecol Obst 74,261-267.

5. Stein IF \& Leventhal ML(1935) Amenorrhea associated with bilateral PCOD. Am J Obstet Gynae 29,181-186.

6. Dunaif A, Givens JR et al . Current issues in endocrinology \& metabolism. PCOS. Boston Blackwell.

7. Laakso M 1993.How good a marker is insulin level for Insulin resistance ? Am J Obstet Gynae 137,959-965.

8. American Diabetic Association 1998. Consenses Development Conference on Insulin Resistance;5-6 November 1997. Diabetes care21;310-314.

9. Foley JE, Kashiwagi A, Chang H, Huecksteadt et al 1984 Sex differences in insulin stimulated glucose transport in rat \& human adipocytes. Am J P hysio246; E211-215.

10. Ovensen P,Moller J, Ingerslev HJ, Jorgensen JOL, Mengel A, Schmitz O,George K, Albert MM, Moller N 1993 Normal basal \& Insulin stimulated fuel metabolism in lean women with PCOS.J Clin Endocrin Metab 77;163640.

11. Carey AH,Chan KL, Short F, White DM, Williamson R, Franks S 1993.Evidence for a single gene effect in PCOD and male pattern baldness. Clin Endoc (Oxf) 38;653-658. 